\title{
COSTA RICA 2016: ELECCIONES, PARTIDOS CANTONALES Y AUTONOMÍA LOCAL
}

\author{
COSTA RICA 2016: ELECTIONS, CANTONAL PARTIES AND LOCAL \\ AUTONOMY
}

Eduardo Frajman

Recibido: 22/05/2016 Aceptado: 28/06/2016

\begin{abstract}
Resumen
El presente estudio bosqueja la participación de partidos cantonales en las elecciones municipales del 2016 y analiza el papel que, desde su perspectiva, juegan en la arena política nacional. El estudio se basa en el análisis cualitativo de informes mediáticos, documentos oficiales de los partidos y entrevistas telefónicas con líderes partidarios. La principal conclusión es que los partidos cantonales se consideran partícipes en un proceso de redemocratización nacional fundamentado en la actividad política local de base. Son conscientes, al mismo tiempo, de los importantes obstáculos que les impiden adquirir protagonismo en la política nacional.

Palabras clave: Costa Rica; partidos cantonales; política local; descentralización; democracia.

Abstract

The presence and importance of county-level political parties in Costa Rica has increased over the last two decades. This study outlines the participation of county-level parties in the municipal elections of 2016 and analyzes the role that, from their own perspective, they play in national politics. The study is based on a qualitative analysis of media reports, party documents and telephone interviews with party leaders. The main conclusion is that county-level parties see themselves as participating in a process of national redemocratization founded on local grassroots political activity. They are aware, at the same time, of the important obstacles that stand in their way of gaining protagonism in national politics.
\end{abstract}

Keywords: Costa Rica; county-level parties; local politics, decentralization; democracy. 


\section{Introducción}

Las elecciones municipales celebradas en Costa Rica el 7 de febrero del 2016 marcaron el inicio de una nueva etapa en la política nacional. Por primera vez, los comicios para todos los puestos a nivel municipal se llevaron a cabo en total independencia de aquellos para cargos nacionales y en un año diferente. Por ende, por primera vez se dio el fenómeno de "elecciones de medio periodo" (Soto Zúñiga, 2015), mediante las cuales los votantes pudieron expresar sus preferencias sobre los candidatos locales y manifestar, indirectamente, sus opiniones sobre el desempeño de la administración presidencial y la Asamblea Legislativa desde el 2014.

El propósito de la separación de los dos procesos electorales fue aumentar el perfil de los gobiernos municipales frente a una ciudadanía alarmantemente apática y desinformada. Una campaña dedicada, en exclusiva, a candidatos y cuestiones municipales tendría el potencial de capturar fácilmente la atención de los electores (Mora Alfaro, párr. 3). Es ahora evidente que esta corrección al proceso ha sido, hasta cierto punto, exitosa.

Dado el descontento popular con las élites políticas nacionales (Programa Estado de la Nación 254; Alfaro Redondo y Gómez Campos 130), activistas en localidades de toda Costa Rica han buscado afectar la arena política municipal, al esquivar las estructuras establecidas por el hegemónico statu quo; principalmente a través de partidos políticos a nivel provincial y, especialmente, cantonal.

La proliferación de partidos locales tiene un impacto salubre en las democracias (Boogers y Voerman, 76-77; Kjaer y Elklit, 429; Elmendorf y Schleider, 403-405); por ejemplo, en Costa Rica, la percepción de los partidos cantonales es generalmente positiva (Gómez Campos y Sáenz Bonilla 2015; Castro Ávila 2015), pero, determinar el efecto real de los partidos cantonales en la calidad de la democracia costarricense requerirá de un cuidadoso seguimiento de su desempeño electoral y de las acciones de sus representantes en posiciones gubernamentales.

El presente trabajo ofrece una contribución inicial al presentar un esbozo de la participación de los partidos cantonales en las elecciones municipales del 2016 desde su propia perspectiva. Las preguntas que impulsan el estudio son: ¿de qué manera entienden los líderes y activistas de los partidos cantonales su propio papel en la política costarricense?, ¿cuál es el ímpetu que provoca la creación de, y participación en, tales organizaciones? Para responderlas es necesario descubrir los fundamentos ideológicos de los partidos, así como los objetivos y anhelos de sus participantes. Además, se requiere colocar a los partidos cantonales en el contexto histórico del ámbito electoral costarricense y analizar el efecto que los partidos locales han tenido, y continúan teniendo, en la política nacional.

De este modo, el estudio aborda el análisis textual cualitativo de diversas fuentes de información. Dicho método de investigación, basado en la lectura detallada 
de un número relativamente pequeño de textos (los cuales pueden ser escritos, orales o visuales), en contraste con el análisis cuantitativo de extensos puntos de datos, resulta ideal para explorar casos específicos en forma minuciosa. Dada la limitada información disponible sobre partidos locales en Costa Rica, es necesario dar el paso inicial para comprender adecuadamente este fenómeno. El análisis cuantitativo estimula la flexibilidad en la identificación de categorías para la observación (Bryman 542).

Las siguientes fuentes forman la base del análisis: 1) la cobertura mediática de la campaña electoral, especialmente los periódicos La Nación, Diario Extra, La República y Cosa Rica Hoy; 2) materiales de campaña producidos por los mismos partidos, accesibles en páginas virtuales y como presencia en "redes sociales" como Facebook y Twitter; 3) los estatutos oficiales de cada uno de los partidos, presentados al Tribunal Supremo de Elecciones (TSE) como requerimiento de inscripción electoral, accesibles en la página virtual del TSE; 4) entrevistas telefónicas con representantes en posiciones de liderazgo de varios partidos cantonales.

La principal conclusión del estudio es que los líderes y activistas de los partidos cantonales en Costa Rica se consideran partícipes de un proceso de "redemocratización" nacional, dado que entienden a los partidos nacionales dominantes como antidemocráticos e interesados en monopolizar el poder en la política nacional. Dada su confianza en las instituciones electorales del país, especialmente el TSE, expresan confianza en su capacidad de efectuar cambios en la política costarricense mediante la participación en comicios municipales. Aunque han tenido éxito en aumentar su presencia en los gobiernos municipales, su impacto es aún pequeño y, dada la lentitud de su avance y la enraizada presencia de los partidos tradicionales, lo continuará siendo en el futuro cercano.

\section{El sistema municipal en Costa Rica}

Costa Rica está dividida en 81 cantones, y cada uno de estos en distritos administrativos. De acuerdo con la división territorial actualizada ante las elecciones municipales del 2016, Costa Rica cuenta con 474 distritos. Cada cantón lo encabeza un alcalde, elegido popularmente como parte de una papeleta que incluye también dos vicealcaldes del mismo partido. El alcalde dirige la administración municipal y articula los intereses de los diferentes actores del gobierno local; además, atiende las sesiones del consejo municipal, con voz pero sin voto.

Al mismo tiempo, cada cantón cuenta también con un concejo municipal, compuesto por cinco, siete, nueve, once o trece regidores municipales. El tamaño del concejo es determinado por la fórmula de proporción por población establecida en el Código Municipal. Los regidores municipales son electos como parte de listas partidarias. La presencia de los diferentes partidos en los consejos municipales se determina por la fórmula de representación proporcional conocida como el "coeficiente de Hare". ${ }^{1}$ 
Los partidos deben presentar una lista paralela de regidores suplentes. Aunque el consejo municipal tiene la potestad de crear ordenanzas locales y determinar la distribución del presupuesto municipal, es generalmente sabido que la autoridad real yace en el alcalde.

Cada distrito administrativo es representado por un síndico (y su suplente) y cuatro miembros del consejo de distrito (con sus suplentes). Las autoridades distritales tienen muy pocas potestades reales más allá de consideración, deliberación y asesoramiento a las autoridades cantonales y estatales sobre temas de interés local. En ocho distritos existen además las posiciones de intendente y concejales municipales de distrito (y suplentes), cuya autoridad es similar a la de los oficiales cantonales. Las autoridades distritales se eligen proporcionalmente como parte de las papeletas partidarias.

Todos los partidos deben respetar los requerimientos de la Ley de Paridad de Género: un número idéntico de hombres y mujeres entre sus candidatos, al igual que la intercalación de género en las listas partidarias (Zamora, 6-8). En total, 6069 oficiales públicos fueron elegidos en febrero del 2016.

\section{Contexto histórico}

Los partidos cantonales han formado parte del sistema político costarricense desde 1953 (Blanco Lizano 164). Sin embargo, el proceso de separación de las elecciones nacionales y municipales, comenzando en 1998 con las reformas al Código Electoral y culminó con el establecer del actual sistema en el 2009, ha creado nuevos incentivos y oportunidades para el surgir de un gran número de partidos locales. En sus primeras encarnaciones, los partidos cantonales en Costa Rica no representaban intereses locales, sino que fueron utilizados, sobre todo, como plataformas para que los políticos con ambiciones nacionales pudieran lanzar sus carreras en ambientes favorables (Blanco Lizano 165). No obstante, desde 1998, una nueva generación de organizaciones ha resucitado el ímpetu a la actividad política a nivel municipal, especialmente en la provincia de San José. Siguiendo el ejemplo de estos pioneros, los partidos cantonales se han multiplicado, y en la actualidad tienen presencia en las siete provincias.

Hasta el año 2002, la política local en Costa Rica estuvo dominada por las mismas fuerzas protagonistas en la política nacional: el Partido Liberación Nacional (PLN) y el Partido Unidad Social Cristiana (PUSC). La posición entre los dos partidos reflejaba su éxito (o falta de este) nacionalmente. Así, cuando el PLN ganó la presidencia y la mayoría de diputados en la Asamblea Legislativa, como ocurrió en 1982, 1986 y 1994, ganó también la mayoría de alcaldías, regidurías y sindicalías. Cuando el PUSC salió victorioso en las elecciones nacionales de 1990 y 1998, el resultado fue similar a nivel municipal (Alfaro Redondo 102).

Un resultado del dominio los partidos tradicionales, pero también del creciente descontento popular, fue la reaparición de organizaciones políticas locales con ambiciones 
electorales. Ocho partidos cantonales se inscribieron con el TSE para participar en los comicios municipales de 1998 (Blanco Lizano 2), y a lo largo del tiempo el número ha aumentado progresivamente; por ejemplo, en el 2010 pasó a 25 y a 56 en el 2016. En este último año, por lo menos un partido cantonal fue representado en 40 de los 81 cantones.

En 1998, la Yunta Progresista Escazuceña, en el cantón de Escazú, condujo la campaña más exitosa, pues alcanzó la alcaldía, mayoría en el consejo municipal y varios consejos de distrito. Por su parte, el partido Del Sol en Santa Ana, el partido Curridabat Siglo XXI en Curridabat y el Partido Humanista de Montes de Oca consiguieron regidurías y concejalías de distrito, tomando un primer paso hacia la competitividad electoral (Blanco Lizano 179).

Las elecciones del 2002 mantuvieron el patrón establecido -el candidato del PUSC fue electo presidente, y ese partido conquistó la mayoría de los escaños legislativos, alcaldías, y el resto de los funcionarios municipales-, pero el sistema político costarricense comenzó a presentar síntomas de una importante transformación. La aparición del Partido Acción Ciudadana (PAC) fue de vital importancia. La inesperada popularidad de su candidato presidencial forzó a los candidatos de los dos partidos mayoritarios a una segunda ronda electoral, un evento sin precedentes en la historia costarricense.

El 2002 vio el lanzamiento de un nuevo sistema electoral, a partir de la reforma al Código Municipal aprobada por la Asamblea Legislativa en 1998, de acuerdo con el cual algunos de los puestos municipales serían elegidos en comicios exclusivos, a llevarse a cabo en noviembre del año electoral (Blanco Lizano 2). Una crucial consecuencia de este cambio fue el altísimo nivel de abstencionismo durante los comicios municipales, que sobrepasó el 70 por ciento de los electores.

Los partidos cantonales mantuvieron su presencia en este nuevo contexto, pero no la extendieron. Esto demostró que un aumento en el número de partidos no lleva necesariamente al crecimiento de su presencia en puestos electivos. Mientras que ocho partidos participaron en la contienda de 1998, 19 se inscribieron en el 2002, mas su presencia en gobiernos locales no aumentó (Alfaro Redondo 98). La Yunta Progresista Escazuceña perdió la alcaldía en su cantón, mientras que el candidato de Curridabat Siglo XXI triunfó en la suya. El Partido Humanista de Montes de Oca no logró duplicar su actuación previa, y el Partido Del Sol formó una alianza con el PAC para contrarrestar el poder del PLN. Esta estrategia ha sido desde entonces adoptada por varios partidos locales (Blanco Lizano 179).

El reordenamiento del sistema partidario costarricense se agudizó en el 2006, en una dirección distinta a la anticipada. En lugar de un balance de poder tripartidista, los resultados electorales revelaron la primacía del PLN, el estancamiento del PAC y el estrepitoso colapso del PUSC. Aunque el líder del PAC, Ottón Solís, estuvo cerca de ganar la presidencia, el candidato del PLN, el expresidente Óscar Arias, resultó victorioso. 
El PLN consiguió también una importante mayoría en la Asamblea Legislativa, pero fue en el ámbito municipal que su nueva posición como indiscutible potencia de la política costarricense se hizo más evidente. Los candidatos liberacionistas conquistaron 59 alcaldías (73 por ciento de los cantones), y mayorías abrumadoras en el resto de los puestos municipales. Esta dominancia continuó en el 2010, cuando los oficiales electos en este año mantuvieron su cargo por un período extendido (del 2010 al 2016), dadas las reformas al Código Municipal que separaron las elecciones nacionales de las municipales.

El número de partidos cantonales continuó en aumento, pero su impacto electoral fue mínimo. Además, ganaron solo tres alcaldías en el 2006 y dos en el 2010. Aunque lograron posicionar más de sus miembros en concejos municipales, distritales y sindicalías, el dominio de los partidos mayoritarios se mantuvo firme.

Figura 1

CONTROL DE ALCALDÍAS POR PARTIDO POLÍTICO

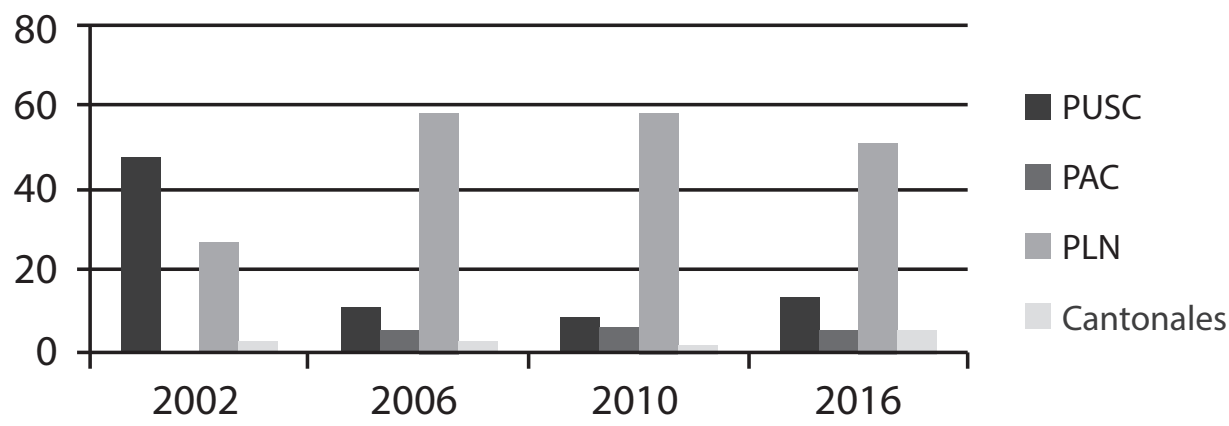

Fuente: Tribunal Supremo de Elecciones.

\section{Las elecciones municipales del 2016}

En anticipación a las elecciones municipales, muchos de los líderes y activistas de los partidos cantonales consideraban al 2016 como una oportunidad para enraizar su presencia e impacto en la política nacional. Pese a la dominancia financiera de los partidos mayoritarios, los partidos locales contaban con la cobertura mediática y la atención exclusiva en las elecciones municipales, para avivar su perfil frente a la ciudadanía electora. Los resultados electorales del 2014 aparentaban ser propicios para un nuevo ordenamiento en la política nacional. 
Figura 2

CONTROL DE REGIDURÍAS POR PARTIDO POLÍTICO

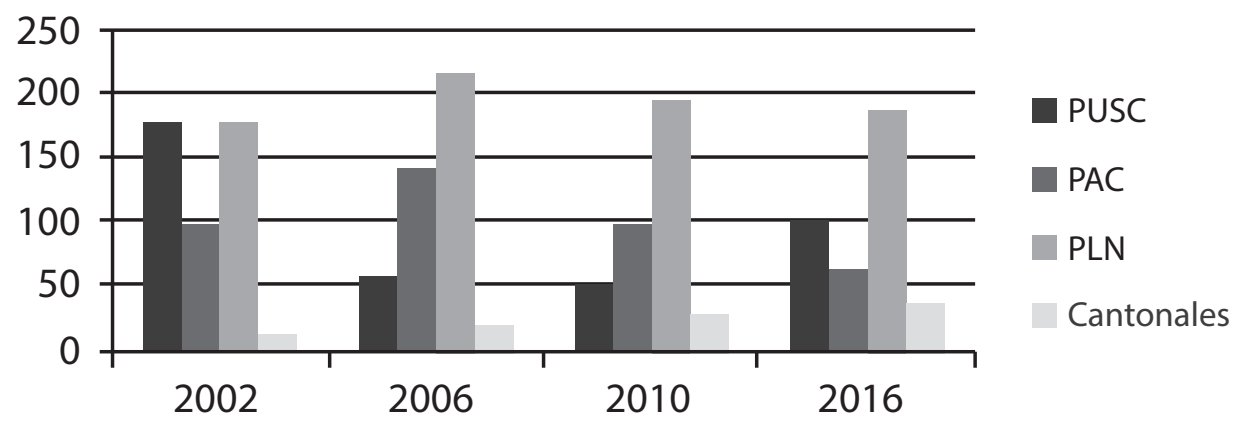

Fuente: Tribunal Supremo de Elecciones.

Luego de una década de primacía, el PLN se mostró debilitado e impopular (Cerdas, párr. 2); en especial porque perdió varios escaños en la Asamblea Legislativa y su candidato presidencial, Johnny Araya, sufrió una espectacular derrota frente al eventual ganador, Luis Guillermo Solís del PAC. La celebración del PAC fue de corta duración; sin embargo, Solís se mostró indeciso y poco carismático, y ha sido incapaz de capturar el apoyo de gran parte de la población (Navarro Leiva, párr. 1). Ambos campos, por lo tanto, mostraban señales de vulnerabilidad (Salas, párr. 6).

Por su parte, las fuerzas políticas nacionales también se han multiplicado, al presentar importantes retos a los partidos cantonales. En las elecciones del 2016, el PUSC buscaba dar un paso hacia su regreso a la prominencia (Solano, párr. 3). Mientras que los partidos nacionales minoritarios, como el Frente Amplio, el Movimiento Libertario, los partidos Accesibilidad sin Exclusión, Renovación Costarricense, Nueva Generación, entre otros planeaban aprovechar el retraimiento del PLN y del PAC.

Figura 3

CONTROL DE SINDICALÍAS POR PARTIDO POLÍTICO

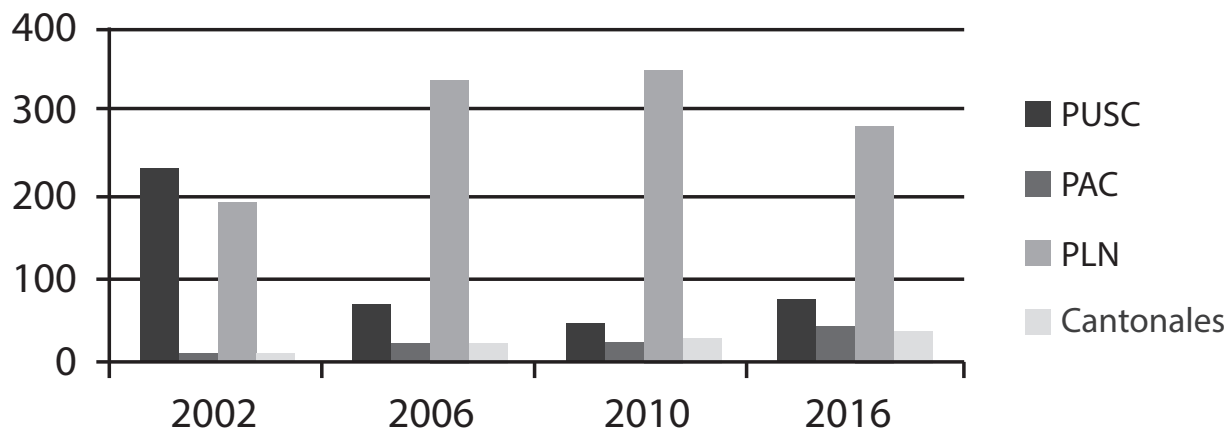

Fuente: Tribunal Supremo de Elecciones. 
Debido a que se esperaba un alto nivel de abstencionismo, la cobertura mediática de la campaña electoral fue limitada. Los periódicos y canales televisivos de alcance nacional cumplieron su obligación cívica: publicaron información sobre los diferentes cantones y ofrecieron espacios para que los candidatos a las alcaldías se presentaran al público. Sin embargo, se ofreció cobertura específica sobre compañas y temas de interés local. La excepción se dio en el cantón central de San José, donde varios partidos compitieron por la alcaldía, incluyendo Alianza por San José, un partido cantonal creado exclusivamente para apoyar la candidatura del excandidato presidencial del PLN, Johnny Araya.

Los resultados de las elecciones ofrecieron algunas sorpresas, pero en general cumplieron con las expectativas. El PLN mantuvo su primacía, pero perdió un poco de terreno, pues de controlar 59 alcaldías en el 2010 pasó a 48. El PUSC fue el mayor beneficiario, aumentando su control de 9 alcaldías en el 2010 a 12 en el 2016, y mostrando avances similares en otros puestos gubernamentales. La actuación del PAC fue decepcionante, la impopularidad del presidente Solís resultó ser un obstáculo demasiado difícil de superar. Por su parte, el Movimiento Libertario y el Partido Renovación Costarricense sufrieron pérdidas importantes, mientras que el Frente Amplio, el Partido Nueva Generación y el Partido Republicano Social Cristiano (un vástago del PUSC) lograron establecerse en un puñado de alcaldías. En términos generales, el abstencionismo fue menor que en elecciones recientes pero aun así un altísimo 65 por ciento.

Los partidos cantonales mejoraron su posición en la arena electoral, pero continuarán siendo actores secundarios en la política costarricense, por lo menos hasta el 2020. La cantidad de concejalías y sindicalías en manos de partidos cantonales aumentó significativamente, pero aún es limitada en relación con los mayores partidos nacionales. Yunta Progresista Escazuceña y Curridabat Siglo XXI conquistaron las alcaldías de sus respectivos cantones, así como Alianza por San José y el Partido Auténtico Limonense; aunque estos dos últimos se distinguen de la mayoría de los partidos cantonales por ser vehículos de personalidades previamente afiliadas al PLN -Johnny Araya en San José y Néstor Mattis en Limón-. 
Figura 4

CONTROL DE CONSEJALÍAS DE DISTRITO POR PARTIDO POLÍTICO

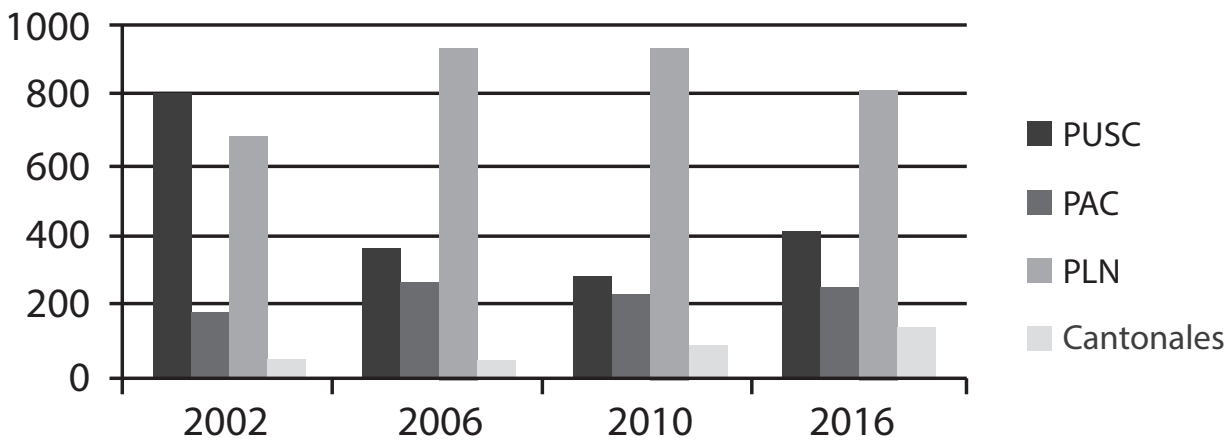

Fuente: Tribunal Supremo de Elecciones.

Es razonable predecir que las organizaciones partidarias de base continuarán estableciendo su posición en las sedes de gobierno local, pero esta continuará siendo bastante limitada. Esta es la opinión de los líderes partidarios entrevistados para este estudio, para quienes la diferencia entre los recursos financieros disponibles a los partidos nacionales y a los cantonales resulta abrumadora, a corto plazo insuperable, especialmente dada la necesidad de educar a una ciudadanía apática y desinformada. Además, sostienen que el progresivo distanciamiento entre los gobiernos municipales y el electorado ha perjudicado sobremanera la capacidad de las instituciones públicas de actuar independientemente; para otros, la proliferación de partidos locales en algunos casos perjudica la capacidad de estos de atraer apoyo y votos, dada la competencia entre grupos emergentes. A su vez, varios de los entrevistados se muestran optimistas, en especial dado el ejemplar desempeño de la Yunta Progresista en Escazú y Curridabat Siglo XXI.

\section{Los partidos cantonales costarricenses en el 2016}

Siendo organizaciones políticas de base con intereses primariamente locales, los partidos cantonales difieren enormemente en sus intereses, membresía, actividades electorales y muchas otras cualidades. Esto no es sorpresivo si se consideran las enormes diferencias entre los cantones del país. Costa Rica cuenta con cantones urbanos, semiurbanos y rurales, montañosos y costeños, afluentes y pobres, industriales y agricultores (Castro Ávila, 9-11). Un partido en el cantón de Tibás, que cubre un área de ocho kilómetros cuadrados, no tendrá los mismos objetivos que un partido en San Carlos de Alajuela, con un área superior a los 3000 kilómetros cuadrados. De la misma manera, un partido en el cantón central de San José, cuya población es de más de 300000 habitantes, no se comportará de la misma manera que un partido en Hojancha de Guanacaste, donde la población supera apenas las 7000 personas. 
Las similitudes, sin embargo, son evidentes. Todos los partidos locales tienen esencialmente la misma estructura, basada en las directrices establecidas por el TSE. Estas incluyen la celebración de una asamblea constitutiva, la designación de un comité ejecutivo, la formación de tribunales internos de alzada, ética y disciplina, las elecciones internas, la presentación pública del nombre, divisa y estatutos, y los principios ideológicos del partido. El TSE impone una serie de mandatos a los partidos políticos como condición para participar en elecciones: manifestación de no subordinación política, respeto a la Constitución Nacional, a la paridad de género, a la libre expresión y varios otros principios fundamentales, el requerimiento de formar asambleas cantonales y distritales, reglamentos el funcionamiento de las estructuras partidarias, y demás (Departamento de Registro de Partidos Políticos, 6-10).

Cabe recalcar que la presencia de partidos cantonales ha sido históricamente mucho mayor en la provincia de San José (Blanco Lizano 166). A pesar de la germinación de estos partidos en las siete provincias, la mayoría continúa teniendo base josefina.

Tabla 1

PARTIDOS CANTONALES INSCRITOS EN LAS ELECCIONES DEL 2016, POR PROVINCIA

\begin{tabular}{lc}
\hline Provincia & Partidos \\
\hline San José & 24 \\
Alajuela & 9 \\
Cartago & 4 \\
Heredia & 5 \\
Guanacaste & 1 \\
Puntarenas & 9 \\
Limón & 5 \\
\hline
\end{tabular}

Fuente: Tribunal Supremo de Elecciones.

Varios estudios recientes, concentrados en Europa y Estados Unidos, mantienen que la proliferación de partidos políticos con intereses exclusivamente locales es saludable para la democracia. Al respecto, Marcel Boogers y Gerrit Voerman (76-77) afirman que los partidos locales son eficientes, ya que su actividad se concentra en un número relativamente pequeño de activistas, lo cual minimiza conflictos internos. Boogers y Voerman encuentran que la actividad partidaria local enriquece el debate democrático, recalcando las diferencias entre intereses locales y nacionales, y creando espacios para nuevas críticas al sistema político tradicional y nuevas demandas a 
sus líderes. Christopher Elmendorf y David Schleicher concuerdan, añadiendo que el énfasis en cuestiones locales tiene el potencial de atraer el interés ciudadano de una manera distinta a los partidos nacionales, cuyas plataformas políticas están generalmente basadas en fundamentos ideológicos. El dominio de partidos nacionales tiende a "nacionalizar la política local", poniendo de lado las importantes, incluso urgentes, necesidades de comunidades específicas (Kjaer y Elklit, 429).

Un estudio reciente realizado en Costa Rica por investigadores del Proyecto Estado de la Nación identifica tres contribuciones de los partidos cantonales a la vida política local: la de organizar campañas electorales, la agregación de intereses locales y la socialización política de los ciudadanos (Gómez Campos y Sáenz Bonilla 2). En sus documentos oficiales y a durante entrevistas telefónicas, los líderes de estos partidos enfatizan precisamente esas actividades como cruciales para la revitalización de la democracia en Costa Rica. Para lograrla, sin embargo, es necesario promover un cambio fundamental al sistema político costarricense.

"En un proceso que lleva más de cuarenta años", declaran los estatutos de la Yunta Progresista Escazuceña, "los gobiernos y los partidos han pervertido y sofocado la vida municipal" (1). La centralización del poder político, de acuerdo con el Partido Demócrata, es dañina para la democracia porque "no permiten el ingreso a la vida política de nuevos valores" (1). En tales condiciones, afirma el Partido Progreso Comunal Desamparadeño: "la relación de la ciudadanía y el gobernante en ejercicio se vuelven más burocráticos y hacen más distante la participación de la ciudadanía en los problemas, se torna disociable e inalcanzable, es decir, el poder está en una estructura vertical" (5). La más calcinante crítica al bipartidismo es articulada en los estatutos de Alianza por San José, el partido del exliberacionista Johnny Araya:

La municipalidad no puede continuar con las politicas de los partidos tradicionales y minoritarios, quienes han escogido, con muy contadas excepciones, a personas cuyos intereses son muy diversos, pero siempre personalísimos: desde servirse del cargo público o administrativo en la corporación municipal para lograr negocios "oscuros" con los dineros públicos o como "trampolín político" para optar a un puesto político de mayor rango (diputado, ministro o cónsul) hasta por mero protagonismo ególatra o vanidad personal (4).

Es imprescindible, por lo tanto, movilizar a la ciudadanía para revertir este proceso. “Después de la euforia centralizadora de los servicios que se abatió sobre nuestro país desde fines del siglo pasado" afirma el Partido El Puente y los Caminos de Mora, "ahora se empieza a reconocer las ventajas de la descentralización" (2). El Partido Del Sol declara que "la renovación y la revitalización de la Municipalidad es condición necesaria para el desarrollo de la democracia costarricense” (2). La política local, de acuerdo con el Partido Humanista de Montes de Oca, provee el ámbito idóneo para que "los ciudadanos puedan ejercitar de manera concreta la esencia de la 
democracia, es decir, el poder del pueblo para el pueblo, y donde pueden comenzar a ser dueños de su destino" (6). Alianza por San José concuerda con estas organizaciones: "hoy es necesario que la municipalidad, como base de la democracia costarricense, se transforme en una democracia protagónica de la vida comunal y municipal del cantón" (2). Por su parte, el Partido Acuerdo Cantonal Desamparadeño se propone a "favorecer por todos los medios posibles la democratización y descentralización de las acciones del gobierno local" (2).

Los líderes de partidos cantonales entrevistados para este estudio entienden su participación electoral en términos de democratización y descentralización. El protagonismo de los partidos nacionales no beneficia a las municipalidades, según Leonardo Ramírez del Partido Demócrata, porque "las políticas nacionales no tienen identidad cantonal". Los políticos nacionales no conocen ni se interesan por los problemas de comunidades específicas y, a la vez, dada su ignorancia de situaciones específicas disminuyen su capacidad de resolverlas. Al respecto, Orlando Guzmán Vázquez, de la Liga Ramonense, afirma que existe una "gran lejanía" entre las municipalidades y el Gobierno nacional; incluso cuando los políticos visitan las diferentes comunidades durante los períodos electorales, los oficiales municipales asumen que eso raramente se traducirá en ayuda concreta. "El que gana no cumple", declara Fernando Castillo de Fuerzas Unidas para el Cambio, "el que pierde se olvida".

Los partidos cantonales, mientras se mantienen autónomos e ideológicamente flexibles, "afuera de las argollas políticas", como lo expresa Marianela Lobo del Partido Del Sol, ofrecen alternativas potencialmente atractivas para los votantes. Erick Varela, del Partido Desamparados Unido, mantiene que la "pureza de acción" de las organizaciones locales es su característica más distintiva.

Al mismo tiempo, varios de los entrevistados señalan que la autonomía y transparencia a la cual aspiran los activistas locales no se refleja en todos los partidos cantonales. Algunos han sido creados exclusivamente como vehículos para previos partícipes en la política nacional, como Johnny Araya, alcalde de la ciudad de San José y exmiembro del PLN. ${ }^{2}$ Otros, de acuerdo con lo expresado por las personas entrevistadas, reciben ayuda financiera de los partidos nacionales, y otros existen expresamente para debilitar a sus competidores.

Posteriormente a las elecciones de febrero del 2016, algunos de los líderes partidarios afirmaron -aunque no ofrecen evidencia- que los partidos nacionales "jugaron sucio" a través de sus estrechas conexiones con los conglomerados mediáticos y actividades de campaña impropias. Un entrevistado acusa a partidos mayoritarios de "comprar votos"; "pecamos de muy confiados", dice otro.

A pesar de los obstáculos a un mayor protagonismo en la vida política, los partidos cantonales han desempeñado un papel importante en las campañas electorales en las que han participado, principalmente como generadores de socialización política. Esta, de acuerdo con Steffan Gómez Campos y Juan Pablo Sáenz Bonilla (2015), 
“incluye la creación y actualización del pensamiento político, la renovación de las estructuras partidarias y la formación político-ideológica de sus militantes". En su estudio sobre partidos cantonales recalcan que:

Con respecto a la función de socialización política, destaca que la mayoría de partidos [cantonales] no tienen un fuerte cimiento ideológico bajo los esquemas tradicionales. Es decir, sus militantes no relacionan de manera directa los ideales del partido con ideologías en una escala de izquierda y derecha, como sí ocurre en los partidos nacionales. Las respuestas de los líderes refieren, más bien, a temas concretos de interés local, generalmente aspectos de desarrollo comunal, administración del gobierno local, control de la corrupción o ampliación de la democracia a nivel comunal (5).

No cabe duda que, en sus actividades cotidianas y durante los procesos de campaña electoral, los partidos cantonales en el período 2015-2016 efectivamente dejaron de lado la retórica ideológica y se concentraron en problemas específicos y propuestas concretas. Al mismo tiempo, es importante tomar nota de las similitudes y diferencias entre las visiones de mundo de los diferentes partidos, para así crear un esbozo del espectro ideológico en donde se dieron los comicios.

Un análisis de los estatutos oficiales de cada partido, disponible en la página virtual del TSE, revela una impactante homogeneidad en los principios fundamentales articulados por las distintas organizaciones. Se hace evidente que todos los partidos expresan apoyo a la tradición de la socialdemocracia costarricense, a la justicia social, a la búsqueda del bien común, al Estado nacional de derecho, a la transparencia y honestidad de los servidores públicos, al respeto a las libertades individuales y los derechos humanos, a la tolerancia y el pluralismo, a la paridad de género y a la democracia participativa. Sin embargo, muy pocos manifiestan una identidad cristiana, y los que lo hacen se apresuran a conectar el cristianismo con los valores de democracia y tolerancia. Alianza por Palmares, por ejemplo, afirma su adhesión a los "valores cristianos, del humanismo, de la libertad, solidaridad, igualdad y justicia como principios básicos de nuestra herencia costarricense" (3). Al mismo tiempo, el Partido El Puente y los Caminos de Mora sostienen que "La Iglesia ha enseñado siempre el deber de actuar por el bien común y al hacer esto, ha educado también buenos ciudadanos para cada estado" (6). El más explícito es el Partido Fuerzas Unidas para el Cambio: "el cristianismo para todos los efectos prácticos, constituye la base moral de la ideología y acción política del partido" (3).

Todos rechazan la corrupción, las políticas discriminatorias basada en raza, etnia, credo o género (ninguno de los partidos menciona la orientación sexual), el aglutinamiento del poder en pocas manos y el predominio de las cúpulas del bipartidismo del siglo XX. Se comprometen a beneficiar a todos los sectores sociales de su cantón, a perseguir el desarrollo económico sostenible y a proteger el medioambiente. 
Solo un partido, Alianza por Palmares, se refiere a la inmigración, al sugerir "una política migratoria restrictiva y ordenada pero que valore las necesidades del mercado acompañado de políticas públicas que busquen generar presión al sistema de seguridad social y que no violente los derechos humanos del inmigrante" (8).

Por su parte, el análisis de los documentos señala también importantes diferencias de enfoque entre los partidos. En términos generales, se destacan tres tendencias. La primera hace énfasis en la importancia de la justicia social y la equidad económica. Por ejemplo, para el Partido Acción Quepeña resulta importante "alejarse de las estructuras tradicionales, que han mantenido reprimidas la energía espiritual y creadora de los pueblos y condena a las grandes mayorías a la pobreza absoluta" (2). El Partido Cívico de Tibás Fuenteovejuna menciona su rechazo a "las políticas que fomentan la concentración de la riqueza en pocas manos, ni la práctica mercantil que burle o eluda el marco jurídico" (4). El Partido Barva Unida enarbola como uno de sus principios doctrinarios la "defensa del interés cantonal y nacional frente a todo signo de globalización neoliberal" (4). Asimismo, los partidos Justicia Generaleña y Movimiento Avance Santo Domingo se autodenominan "antineoliberales", mientras que el Partido Restauración Parriteña se declara socialista.

La segunda tendencia enfatiza el crecimiento económico y la eficiencia gubernamental, a lo cual varios partidos subrayan la importancia de proteger la "libertad de empresa, circulación, comercio y reconocimiento de la propiedad privada legítimamente adquirida", entre ellos Alianza por Palmares, Avance de Montes de Oca y Liga Ramonense. Al respecto, la Unión Poaseña "define como prioridad el desarrollo económico del cantón, para lo cual impulsará el sector agrícola, turístico e industrial" (4), y Corredores en Acción afirma que busca "el desarrollo del libre comercio y la eliminación de cualquier forma de barreras comerciales" (3). Mientras que Nueva Mayoría Griega cree en "la iniciativa privada individual o empresarial como herramientas para crear riqueza y reducir la pobreza" (7).

La tercera tendencia no plantea declaratorias excesivamente ideológicas y se concentra en la importancia de la descentralización del poder en Costa Rica y del desarrollo de los gobiernos municipales. Finalmente, están los partidos sin una clara tendencia ideológica o programática. 


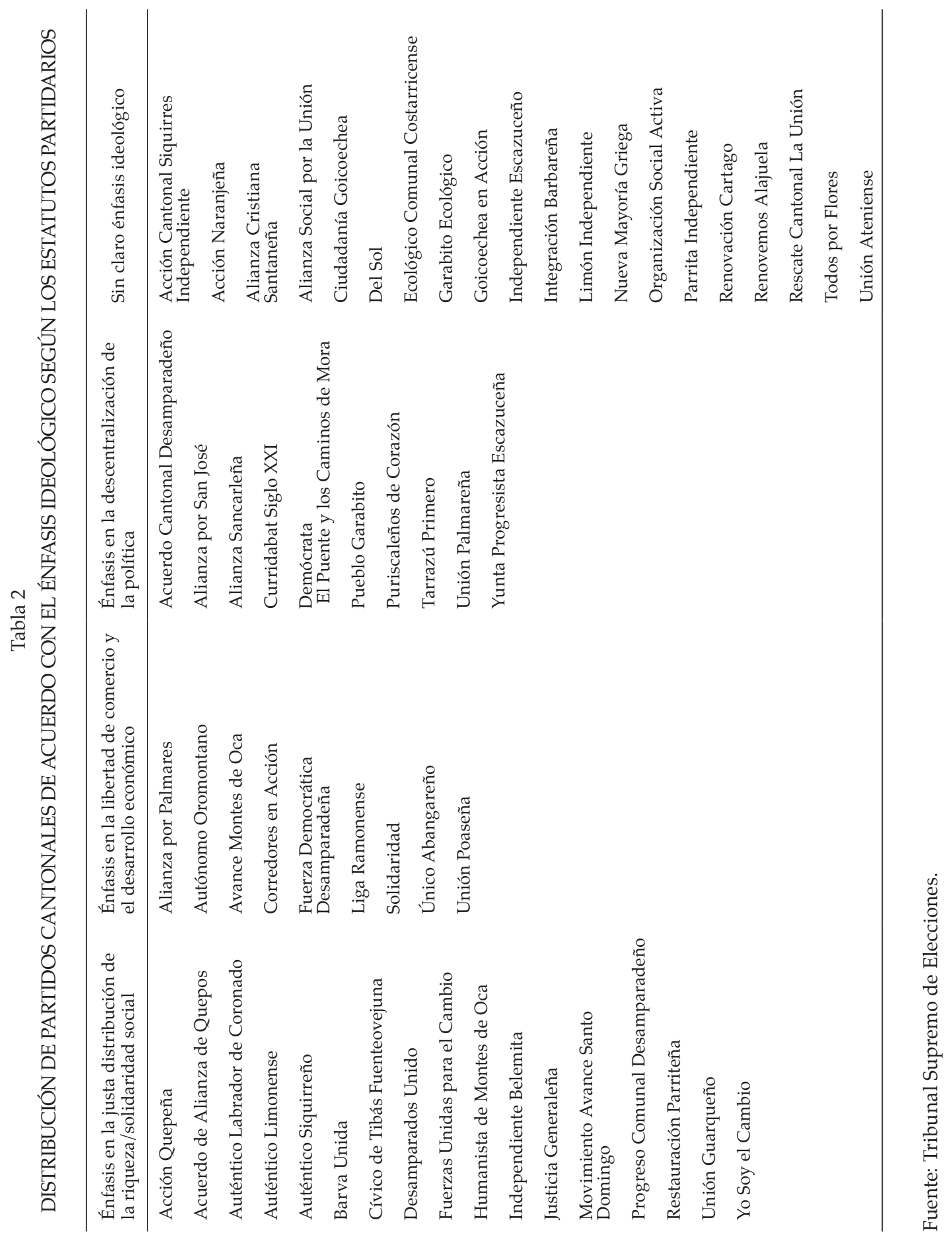


La mayoría de los líderes entrevistados subraya la importancia de la socialización política, pero menos en términos de ideología y más de educar a la población sobre la importancia del gobierno municipal y las importantes diferencias entre los mandatos y potestades del gobierno nacional y los gobiernos locales. Sobre esto, Leonardo Ramírez del Partido Demócrata da el ejemplo de la infame baja calidad de la infraestructura vial en Costa Rica. Los costarricenses se quejan incesantemente de la inacción o incompetencia del gobierno nacional, pero desconocen que gran parte de las vías de tránsito están legalmente bajo el control de los gobiernos municipales, los cuales no reciben los fondos necesarios para afrontar el problema. Al respecto, Carlos Rodríguez Murillo, del Partido Auténtico Labrador de Coronado, menciona también la ineficacia en el ordenamiento del sistema municipal, donde el alcalde tiene demasiada autoridad y el consejo municipal poco poder real.

Sin embargo, los líderes partidarios mantienen un alto nivel de confianza en el sistema político costarricense, fundamentado en la alta estima hacia el TSE. Según los entrevistados, el proceso de inscripción de partidos es sencillo y manejado eficientemente, el TSE ofrece información pertinente, se comporta con transparencia y su trato a los diferentes partidos políticos es equitativo. Siempre y cuando la autoridad electoral funcione con transparencia y eficacia, concluye la mayoría de los entrevistados, los partidos cantonales podrán continuar sus actividades y expandir su presencia electoral. Las lesiones que la democracia costarricense ha sufrido en la historia reciente son importantes e inquietantes, pero no irreversibles siempre y cuando el sistema institucional en Costa Rica mantenga su integridad.

\section{Conclusiones}

Los partidos cantonales en Costa Rica se consideran partícipes en un proceso de redemocratización nacional. Desde su perspectiva, la democracia costarricense ha sido secuestrada por las élites partidarias y los monopolios de poder mantenidos por la burocracia estatal. De acuerdo con su narrativa desarrollada, los líderes de los partidos nacionales tienen interés en centralizar la política para mantener su primacía; esto ha resultado en el abandono de las municipalidades y la disolución de su capacidad para enfrentar los retos que enfrentan las distintas comunidades del país y, consecuentemente, en el deterioro de la calidad de vida de los costarricenses. Mediante la concientización de la ciudadanía a través de la actividad política de base, los partidos cantonales expresan la intención de revertir este proceso. Buscan la descentralización gubernamental y la apertura de espacios para la participación ciudadana en los temas más relevantes a su existencia cotidiana.

En sus documentos oficiales, al igual que en sus materiales de campaña y durante entrevistas efectuadas para el presente estudio, los representantes de los partidos cantonales expresan su certeza de que las organizaciones políticas dominantes a nivel 
nacional han actuado activamente para prevenir la descentralización y la revitalización de la democracia costarricense. Por ende, demuestran gran desconfianza en los partidos mayoritarios y sus liderazgos.

Sin embargo, por el contrario, afirman su total confianza en el sistema institucional, y especialmente en el TSE, al cual ven como una entidad transparente, eficiente y honesta. Aunque existen diferencias ideológicas entre los partidos, estas son superadas de forma abrumadora por sus similitudes; por ejemplo, todos los partidos locales expresan su fidelidad a las tradiciones políticas de la social-democracia costarricense.

El más reciente proceso electoral ha contribuido a mantener esta confianza. Los representantes de los partidos cantonales consideran que el proceso electoral de noviembre y diciembre del 2015 y enero del 2016 fue limpio y acorde con los requerimientos de la democracia. Sin embargo, identifican varios obstáculos para una paridad real que, potencialmente, les permitiría enfrentarse en condiciones equitativas a los partidos nacionales. Estos incluyen las normas de financiamiento de partidos políticos, las alianzas entre ciertos grupos mediáticos y las élites nacionales, el requerimiento de paridad absoluta de género en la representación del partido y el comportamiento electoral de los partidos nacionales.

Los resultados de los comicios del 2016 demuestran que el impacto electoral de los partidos cantonales continúa creciendo. El número de partidos con representantes en gobiernos locales se ha incrementado significativamente, al igual que el número de puestos ocupados por candidatos locales. En este punto cabe recalcar que los resultados, siguiendo el patrón establecido en procesos anteriores, también demuestran que la abrumadora mayoría de los puestos más cruciales del gobierno local -las alcaldíascontinuarán en manos de los partidos nacionales dominantes.

Dada la dificultad de remover la influencia de los partidos mayoritarios, algunos de los líderes entrevistados expresan frustración y pesimismo respecto a la posibilidad de transformar verdaderamente la democracia costarricense. Estiman que el asimiento al poder de las élites partidarias es demasiado fuerte, tal vez inquebrantable. Por su parte, muchos mencionan el éxito de partidos que han conseguido alcaldías y mayorías en consejos municipales, en cantones como Escazú y Curridabat, como inspiración y fuente de optimismo, evidencia que su actividad política, dirigida al mejoramiento de sus comunidades y la reformación de la democracia costarricense, no es en vano.

Esto promueve un cauteloso optimismo. Desde 1998, el número de partidos cantonales en Costa Rica ha crecido rápidamente. Los resultados de las elecciones municipales del 2016 demuestran que su éxito electoral y, por ende, su presencia en gobiernos municipales ha aumentado de forma progresiva. Ante esto, se sugiere que este fenómeno es potencialmente positivo para la democracia costarricense. Ciertamente los partidos cantonales se ven a sí mismos como fuerzas de renovación democrática, a 
través de la actividad política local de base. Hasta qué punto la realidad es conforme a esta percepción es una pregunta empírica que requerirá seguimiento en el futuro.

Es claro que los partidos nacionales con redes de influencia establecidas, especialmente el PLN, mantendrán su dominio en la política local en el futuro cercano. Por eso, los líderes partidarios entrevistados en el presente estudio sostienen que es necesario reformar aún más las instituciones políticas, así como la relación entre el ámbito nacional y el municipal.

Ante esto, se sugieren algunos cambios, por ejemplo continuar reformando la legislación electoral para asegurar la paridad entre los partidos nacionales y los partidos locales, aumentar la atención mediática sobre la política municipal, educar a la ciudadanía sobre la división de responsabilidades y potestades entre el gobierno nacional y el gobierno municipal, aumentar el porcentaje del presupuesto nacional dedicado a los gobiernos municipales, incrementar la accesibilidad de los oficiales municipales a la ciudadanía, y reducir la autoridad del alcalde frente al consejo municipal.

Si los dirigentes y oficiales gubernamentales de los partidos cantonales mantienen el perfil positivo que han adquirido en las últimas dos décadas, continuarán acumulando capital político para presionar a la Asamblea Legislativa a efectuar algunos de estos cambios. Mientras tanto, el debilitamiento del PLN y el PAC, junto al limitado resurgimiento del PUSC, potencialmente augura un futuro político multipolar para Costa Rica. Esto potencialmente beneficia a nuevas, y más pequeñas, organizaciones políticas. Los partidos políticos cantonales, dada la nueva realidad electoral, aparentan estar bien posicionados para profundizar su efecto en la democracia costarricense.

\section{Notas}

1 El coeficiente de Hare es utilizado para calcular el número de votos necesarios para obtener un puesto electoral en un sistema de representación proporcional. Es calculado mediante la división de los votos válidos en las elecciones por el número de puestos elegibles.

Araya fue candidato presidencial por el PLN en las elecciones presidenciales de 2014. A pesar de liderar las encuestas por gran parte del período de campaña, perdió apoyo popular y de su partido progresivamente. En un resultado sin precedentes en la historia de Costa Rica, Araya y el eventual presidente Luis Guillermo Solís emergieron de la primera Ronda de votación. Pero durante la campaña hacia la segunda ronda, se hizo claro que Araya sería derrotado contundentemente, por lo que anunció su retiro de la campaña. Poco tiempo después abandona el PLN y formó Alianza por San José.

\section{Bibliografía}

Auger, Mercedes. "PLN pierde 11 de las 59 alcaldías que mantenía desde el 2010". La Nación, 7 de febrero de 2016. Recuperado de http://www.nacion.com/nacional/Elecciones_ alcaldes-2016-TSE-alcaldias_0_1541245991.html 
Alfaro Redondo, Ronald. "Elecciones municipales y debilitamiento del respaldo electoral bipartidista en Costa Rica, período 1986-2002". Anuario de Estudios Centroamericanos, 28 (2002): 89-135.

Alfaro Redondo, Ronald. “Elecciones nacionales 2006 en Costa Rica y la recomposición del sistema de partidos políticos". Revista de Ciencia Política, 26 (2006): 125-137.

Alfaro Redondo, Ronald. "Elecciones nacionales 2010 en Costa Rica: Una mujer al mando sesenta años después". Revista de Ciencias Sociales, 131 (2010): 101-115.

Alfaro Redondo, Ronald y Steffan Gómez Campos. “Costa Rica: elecciones en el contexto político más adverso arrojan la mayor fragmentación partidaria en 60 años". Revista de Ciencia Política, 34 (2014): 125-144.

Blanco Lizano, Randall. "Los Partidos Cantonales en las Elecciones Municipales de Costa Rica: 1949-2002". Anuario de Estudios Centroamericanos, 28 (2002): 161-186.

Blanco Lizano, Randall. Análisis de las Elecciones Municipales 2010: Resultados, Tendencias y Desafíos. San José: Proyecto Estado de la Nación, 2011.

Boogers, Marcel y Gerrit Voerman. "Independent local political parties in the Netherlands". Local Government Studies, 36 (2010): 75-90.

Bryman, Alan. Social Research Methods. New York: Oxford University Press, 2004.

Cambronero, Natasha. "31 alcaldes lograron reelegirse este domingo en las elecciones municipales". La Nación, 8 de febrero de 2016. Recuperado de http://www.nacion.com/ nacional/politica/alcaldes-reelectos-municipalidades-costa-rica_0_1541445933.html

Castro Ávila, Mariela. Fichero Cantonal 2016. San José, CR: Tribunal Supremo de Elecciones, 2015. Recuperado de http://www.tse.go.cr/pdf/ficheros_municipal2016/fichero_completo.pdf

Cerdas, Daniela "Figueres ante candidatos del PLN: 'Se acabó la vieja forma de hacer política'”. La Nación, 12 de septiembre de 2015. Recuperado de http://www.nacion.com/nacional/politica/Jose-Maria-Figueres-hacer-politica_0_1511648910.html

Departamento de Registro de Partidos Políticos. Constitución e Inscripción de Partidos Políticos. Tribunal Supremo de Elecciones, 2012. Recuperado de http://www.tse.go.cr/pdf/normativa/constitucion_inscripcion_pp.pdf

Elmendorf, Christopher y David Schleicher. "Informing consent: Voter Ignorance, Political Parties and Election Law". UC Davis Legal Studies Research Paper, 285 (2012): 1-70.

Gómez Campos, Steffan y Juan Pablo Sáenz Bonilla. “Organización y Funcionamiento de los Partidos Políticos". Vigésimo Primer Informe Estado de la Nación en Desarrollo Humano Sostenible, 2015. Recuperado de http://www.estadonacion.or.cr/files/biblioteca_virtual/021/politica/Gomez_Campos_Saenz_Bonilla_Partidos_Politicos.pdf

Kjaer, Ulrik y Jørgen Elklit. "Local Party System Nationalisation: Does Municipal Size Matter?". Local Government Studies, 36 (2010): 425-444.

Mora Alfaro, Jorge. "Cinco motivos para votar en las próximas elecciones municipales". Cambio Político, 2015. Recuperado de http://cambiopolitico.com/cinco-motivos-paravotar-en-las-proximas-elecciones-municipales/69066/

Navarro Leiva, Carmen. "Luis Guillermo de los peores en los últimos 40 años". Diario Extra, 23 de setiembre de 2015. Recuperado de http://www.diarioextra.com/Noticia/detalle/270964/luis-guillermo-de-los-peores-en-los-ultimos-40-anos

Programa Estado de la Nación. Vigésimo Informe Estado de la Nación. 2015. Recuperado de http://www.estadonacion.or.cr/20/assets/sinopsis-estado-nacion-20-2014-baja.pdf 
Salas, Giovanni. “Campaña municipal abre fuegos y deja ver tendencias de inicio". Elperiodicocr, 2015. Recuperado de http://elperiodicocr.com/1\%E2\%96\%BA-dia-em-campana-municipal-abre-fuegos-y-deja-ver-tendencias-de-inicio/

Solano, Jacqueline. "PUSC ratifica alcaldes para el 2016". Diario Extra, 6 de setiembre de 2015. Recuperado de http://www.diarioextra.com/Noticia/detalle/269435/pusc-ratificasus-alcaldes-para-el-2016

Soto Zúñiga, Johnny. "Las elecciones municipales de medio periodo". Cambio Político, 22 de junio de 2015. Recuperado de http://cambiopolitico.com/las-elecciones-municipalesde-medio-periodo/65461/

Zamora, Eugenia M. "El principio de paridad en el nuevo código electoral”. Revista Derecho Electoral, 9 (2010). Recuperado de https://www.tse.go.cr/revista/art/9/zamora_chavarria.pdf

Eduardo Frajman. Costarricense. Obtuvo su doctorado en ciencias políticas por la Universidad de Maryland, College Park, Estados Unidos. Se desempeña como instructor adjunto de humanidades y filosofía en Oakton Community College, en Des Plaines, Illinois. Es el editor de contenido de habla hispana en la revista Southern Pacific Review, y contribuye regularmente artículos sobre América Latina a la plataforma digital Lemonwire.com. Es autor de numerosos artículos de investigación, ensayos críticos y literarios, y relatos.

Contacto: efrajman@gmail.com

ORCID: http://orcid.org/0000-0002-1448-4179 